\title{
Retinol exerts therapeutic effect on myocardial infarction through regulation of immune inflammatory cells and Cx43 expression
}

\author{
Hao Sun, Jiuchang Zhong, Xinchun Yang, Zongsheng Guo, Jiamei Liu, Boqia \\ Xie, Yuan Zhang, Xin Wang, Linying Shi, Mulei Chen* \\ Heart Centre, Beijing Chao-Yang Hospital, Capital Medical University, Beijing 100020, China
}

*For correspondence: Email: Mulechen20@yahoo.com; Tel: 0086-10-65951480

Sent for review: 25 June 2020

Revised accepted: 19 April 2021

\begin{abstract}
Purpose: To investigate the effect of retinol on cardiac fibroblast proliferation in vitro and on fibrosis formation in mice in vivo.

Methods: Proliferative potential of fibroblasts was determined using cell counting kit-8 assay. Acute myocardial infarction (AMI) was induced in mice via ligation of the left side coronary artery. In myocardial tissues, concentration of TNF- $\alpha$ was determined using enzyme-linked immunosorbent assay (ELISA) assay.

Results: Exposure to retinol significantly suppressed cardiac fibroblast proliferation under ischemia, when compared to untreated fibroblasts $(p<0.05)$. However, exposure of cardiac fibroblasts to retinol did not produce toxicity at a dose of $10 \mu \mathrm{M}$ under normal conditions. In contrast, exposure to normal levels of oxygen, glutamine and glucose significantly reversed the inhibitory potential of retinol against fibroblasts during ischemia $(p<0.05)$. Treatment of mice with retinol at a dose of $5 \mathrm{mg} / \mathrm{kg}$ reversed the AMI-mediated increase in hydroxyproline level in myocardial tissues. Retinol treatment of AMI mice caused significant elevation in the number of CD31+ capillaries in myocardial tissues. Increase in TNF- $\alpha$ by $\mathrm{AMI}$ in cardiac tissues of mice was reversed by treatment with retinol at a dose of $5 \mathrm{mg} / \mathrm{kg}$. The retinol treatment also caused significant reversal of AMI-induced down-regulation of Cx43 protein $(p<$ 0.05).

Conclusion: Retinol enhanced the proliferation of fibroblasts under ischemic conditions and prevented fibrosis in mice with AMI. Moreover, retinol targeted TNF- $\alpha$ production and upregulated Cx43 expression in myocardial tissues of mice with AMI. Thus, retinol may be useful for the management of myocardial infarction.
\end{abstract}

Keywords: Myocardial infarction, Retinoic acid, Hydroxyproline, Myofibroblasts, Cell proliferation

This is an Open Access article that uses a fund-ing model which does not charge readers or their institutions for access and distributed under the terms of the Creative Commons Attribution License (http://creativecommons.org/licenses/by/4.0) and the Budapest Open Access Initiative (http://www.budapestopenaccessinitiative.org/read), which permit unrestricted use, distribution, and reproduction in any medium, provided the original work is properly credited.

Tropical Journal of Pharmaceutical Research is indexed by Science Citation Index (SciSearch), Scopus, International Pharmaceutical Abstract, Chemical Abstracts, Embase, Index Copernicus, EBSCO, African Index Medicus, JournalSeek, Journal Citation Reports/Science Edition, Directory of Open Access Journals (DOAJ), African Journal Online, Bioline International, Open-J-Gate and Pharmacy Abstracts

\section{INTRODUCTION}

The incidence of acute myocardial infarction (AMI), a severe cardiac disorder that adversely affects human health, is on the increase worldwide [1,2]. Myocardial infarction, also known as heart attack, is caused by occlusion of blood flow to parts of the heart, resulting in death of cardiomyocytes. The cardiomyocyte necrosis is immediately followed by formation of fibrosis 
due to rapid collagen accumulation and fibroblast proliferation $[3,4]$. Fibrosis interferes with normal heart function because of changes in cardiac vascularization and cardiomyocyte regeneration $[3,4]$. At advanced stages, myocardial infarction leads to arrhythmia which is a common type of cardiovascular disorder [1]. Global statistics reveals that ischemic heart disease has a mortality of $13 \%$ and affects mostly developed countries $[3,4]$. Patients suffering from ischemic heart disease are usually kept under close observation because of their susceptibility to arrhythmias [5]. Therefore, development of newer, advanced and more effective treatment for cardiac fibrosis will have tremendous significance in the treatment of myocardial infarction.

Excessive aggregation of inflammatory cells in myocardial tissues and perivasculitis has been reported in patients suffering from myocardial infarction [6]. High levels of interleukins and interferon- $\gamma$ in patients with myocardial infarction indicate that AMI is an inflammatory and non-infectious disease [7]. The involvement of inflammatory responses in the development of myocardial infarction has been previously established [8]. Generally, conventional treatments for cardiac fibrosis target the proliferative as well as migrating potential of fibroblasts $[3,4]$. Transforming growth factor(TGF- $\beta$ ) and endothelin-1 are the most common targets for chemotherapies used for cardiac fibrosis. Moreover, therapies which target angiotensin signaling pathway have been found to be of significance for inhibition of cardiac fibrosis [9]. The present study was carried out to determine the effect of retinol on fibroblast proliferation, with the aim of developing a treatment strategy for AMI.

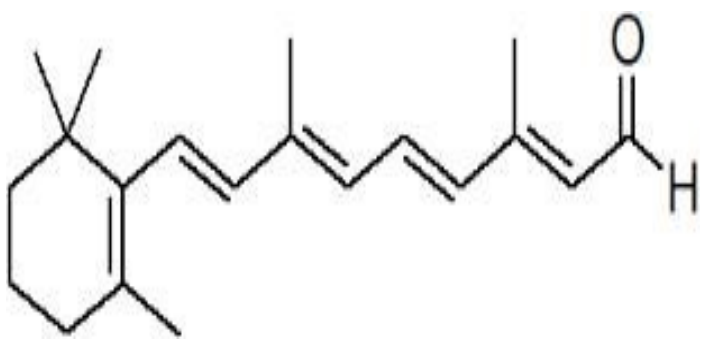

Figure 1: Structure of retinol

\section{EXPERIMENTAL}

\section{Cell viability assay}

Fibroblasts were seeded at a density of $2 \times 10^{6}$ cells/well in 96-well plates containing DMEM mixed with high glucose and FBS (10\%). Exposure of fibroblasts to retinol at a dose of 10 $\mu \mathrm{M}$, or normal saline was continued for $24 \mathrm{~h}$. During incubation with retinol, glucose, glutamine and oxygen levels were maintained at normal levels, while glutamine and glucose, or oxygen and glucose were kept at low levels. Following retinol exposure, the fibroblasts were treated with cell counting kit- 8 solution at $37{ }^{\circ} \mathrm{C}$ for $3 \frac{1}{2}$ h. Multimode detector (BioTek Instrumentation) was used for measurement of optical density at $456 \mathrm{~nm}$, and the values obtained were used to calculate cell viability.

\section{Animals}

Thirty male ICR mice aged about 8 weeks were purchased from the Animal Centre of Jilin University, China. All the animals were kept in animal care facility under controlled temperature $\left(23-24{ }^{\circ} \mathrm{C}\right)$ and humidity $(58 \pm 2 \%)$. The mice were exposed to $12 \mathrm{~h}$ light/12 $\mathrm{h}$ dark cycle and given free access to laboratory feed and water. The animal protocols used were approved by the Committee for Animal Ethics, Beijing Chao-Yang Hospital, Capital Medical University, Beijing, China (approval no. CMU/009/18/09). All protocols were conducted in accordance with guidelines from Animal Care and Use Committee of the US National Institutes of Health [10].

\section{Myocardial infarction and determination of hydroxyl-proline content}

A mouse model of myocardial infarction was established with coronary artery ligation procedure under $1-2.5 \%$ isoflurane anaesthesia injection [11]. Anaesthetization of mice was followed by intubation with intravenous catheter connected to a 20-gauge. Respiration was maintained at 110 cycles per min, and all mice were kept on ventilator. Thoracotomy was used to ligate the coronary artery on the left side using nylon suture approximately $1.5 \mathrm{~mm}$ below the tip of the left auricle. A pale colour of left ventricle confirmed occlusion, and this was followed by stitching to close the chest. Then mice were kept on warm pads till recovery. The same experimental protocol was carried out on mice from the sham group, except that there was no ligation of the coronary artery. Retinol dissolved in physiological saline was administered intragastrically to the mice in treatment group following ligation. On day 15 after ligation, the mice were sacrificed and subjected to histological examination. Hydroxyproline content was measured in myocardial tissues of mice using previously reported protocol [12]. 


\section{Enzyme-linked (ELISA) \\ immunosorbent \\ assay}

Myocardial tissues extracted from mice were minced and then lysed with lysis buffer. Centrifugation was carried out at $600 \mathrm{~g}$ for 30 min at $24{ }^{\circ} \mathrm{C}$, and the supernatant was subjected to assay of TNF-a level using an ELISA kit (ERT2010-1; Assaypro LLC, St. Charles, MO, USA).

\section{Statistical analysis}

Data are presented as mean \pm standard deviation, and were statistically analyzed with SPSS 17.0 software (SPSS, Inc., Chicago, IL, USA). Multigroup comparison was made using One-Way Analysis of Variance (ANOVA). Differences were assumed statistically significant at $p<0.05$.

\section{RESULTS}

\section{Retinol reduced viability of cardiac fibroblasts under ischemia}

Exposure to retinol at a dose of $10 \mu \mathrm{M}$ significantly $(p<0.05)$ suppressed cardiac fibroblast proliferation under ischemia, when compared to untreated fibroblasts (Figure 2). Exposure of the cardiac fibroblasts to retinol at a dose of $10 \mu \mathrm{M}$ did not induce any toxicity under normal conditions. Reduction in retinol-mediated fibroblast viability under ischemia was not reversed by exposure to normal levels of oxygen. Moreover, exposure of fibroblasts to normal oxygen levels and glutamine did not reverse the inhibitory effect of retinol on cardiac fibroblasts during ischemia. However, exposure to oxygen, glutamine and glucose at normal levels significantly $(p<0.05)$ reversed the inhibitory potential of retinol against fibroblasts during ischemia.

\section{Retinol treatment reduced hydroxyproline levels in myocardial tissues}

In myocardial tissues of mice, AMl caused a significant $(p<0.05)$ elevation in hydroxyproline level, relative to normal group (Figure 3 ). However, treatment with retinol at a dose of 5 $\mathrm{mg} / \mathrm{kg}$ effectively reversed the AMI-mediated elevation of hydroxyproline level in myocardial tissues of mice. The suppression of hydroxyproline level by retinol indicated inhibition of cardiac fibroblast proliferation under ischemia, and hence prevention of fibrosis.
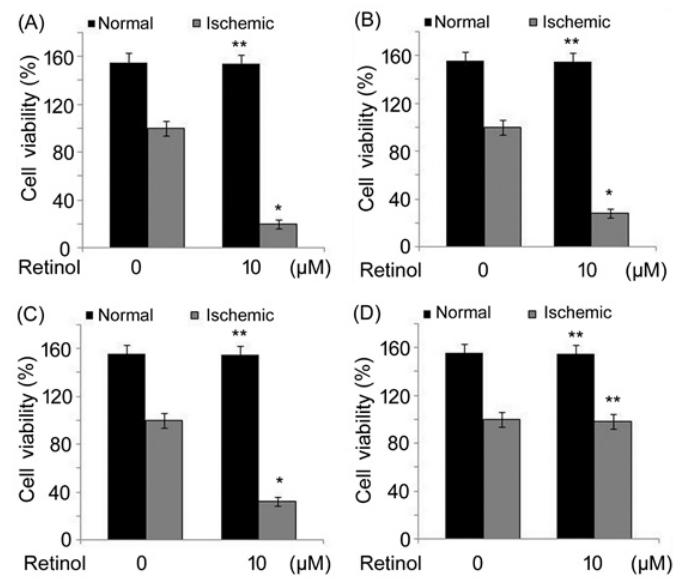

Figure 2: Effect of retinol on viability of cardiac fibroblasts. (A) Cardiac fibroblasts cultured with retinol under normal and ischemic conditions. (B) Cardiac fibroblasts cultured with retinol under ischemia, followed by exposure to normal glucose and oxygen levels. (C) Cardiac fibroblasts cultured with retinol under ischemia, followed by exposure to oxygen and glutamine at normal levels. (D) Fibroblasts exposed to normal oxygen, glucose and glutamine levels after prior treatment with retinol under ischemia. Fibroblast proliferation was determined using CCK-8 assay; * $p<$ $0.02 ;{ }^{* *} p<0.01$, vs. fibroblasts cultured normally

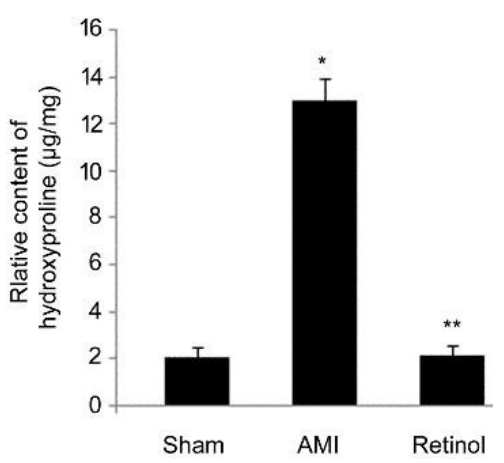

Figure 3: Effect of retinol on content of hydroxyproline in mice with AMI. hydroxyproline levels in myocardial tissues of mice on day 15 following ligation and treatment with retinol at a dose of $5 \mathrm{mg} / \mathrm{kg}$. ${ }^{*} P<0.02$, ${ }^{* \star} p<0.01$, vs. normal mice

Retinol treatment of AMI mice elevated microvascular density

Microvascular density was significantly lower in mice subjected to AMI than in normal mice group (Figure 4). The density of CD31+ capillaries in AMI mice was markedly reduced, when compared to the normal group. However, retinol treatment of AMI mice caused significant elevation of CD31+ capillaries in the myocardial tissues. 


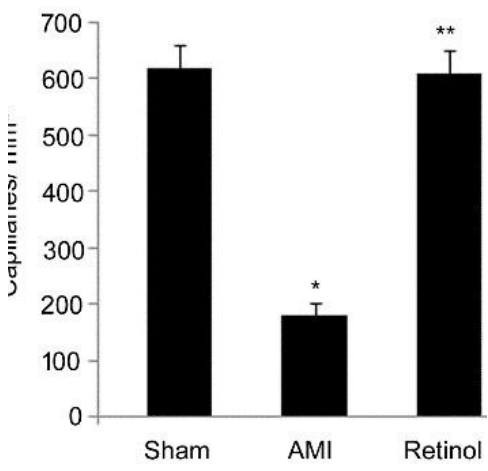

Figure 4: Effect of retinol on microvascular density. The CD31 antibodies were used for determination of microvascular density in cardiac tissues of mice on day 15 following ligation and treatment with retinol at a dose of $5 \mathrm{mg} / \mathrm{kg}$. ${ }^{*} P<0.02,{ }^{* *} p<0.01 \mathrm{vs}$. normal mice. Retinol targeted TNF- $\alpha$ generation in myocardial tissues of mice

In mice cardiac tissues, AMI led to a marked upregulation of TNF- $\alpha$, when compared to normal group (Figure 5). However, the AMI-induced elevation in TNF- $\alpha$ in cardiac tissues of mice was significantly reduced on treatment with retinol.

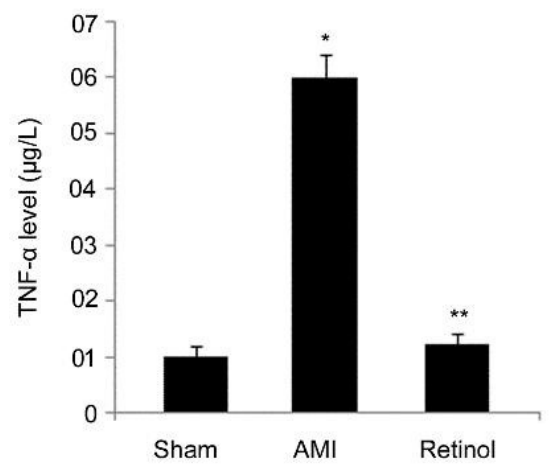

Figure 5: Effect of retinol on TNF- $\alpha$ generation in AMI mice. In vehicle- and retinol-treated mice, TNF- $\alpha$ levels in myocardial tissues on day 15 after ligation were measured using ELISA. ${ }^{\star} P<0.02$, ${ }^{* *} p<0.01$, vs. model control

\section{Retinol elevated the protein expression of Cx43}

Mice subjected to AMI showed relatively lower Cx43 protein levels in myocardial tissues than mice in control group (Figure 6). In AMI mice, Cx43 protein distribution in ventricular tissues was random and prominently reduced, when compared to normal mice which had uniform and higher $\mathrm{Cx} 43$ protein distribution in ventricular tissues. However, retinol at a dose of $5 \mathrm{mg} / \mathrm{kg}$ caused significant $(p<0.05)$ elevation of Cx43 protein in AMI mice.

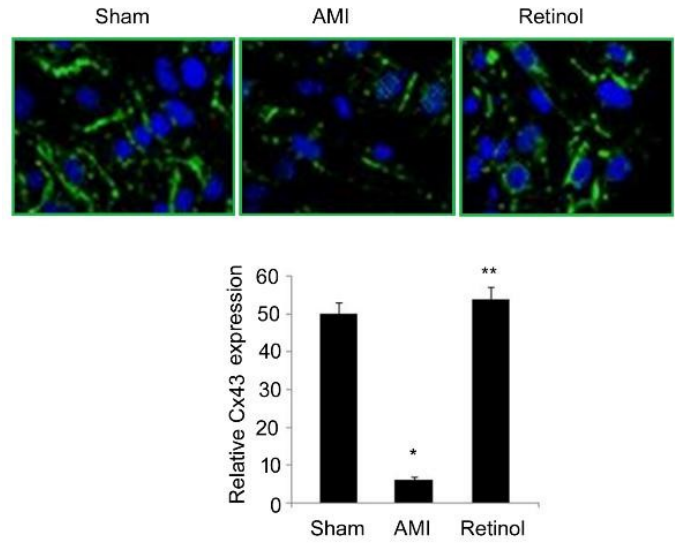

Figure 6: Effect of retinol on $\mathrm{Cx} 43$ protein level. In vehicle as well as retinol-treated mice, Cx43 protein expression in myocardial tissues on day 15 after ligation was measured using inverted microscope assay. ${ }^{*} P<0.02,{ }^{* *} p<0.01$, vs. model control

\section{DISCUSSION}

The current study has demonstrated that retinol exerted cytotoxic effect on ischemic fibroblasts under in vitro conditions, and an anti-fibrotic effect on mice with AMI. Investigations have shown that proliferation of cardiac fibroblasts was suppressed under ischemic conditions by pyrvinium pamoate [13]. It has been established that ligation of the left side coronary artery is usually followed by apoptosis of cardiomyocytes in the ventricular walls due to ischemia [13]. Proliferation is rapidly induced in cardiac fibroblasts, leading to collagen secretion and deposition in myocardial tissues, and fibrosis formation [13].

In the present study, it was found that exposure to retinol significantly targeted proliferative potential of cardiac fibroblast under ischemia conditions. The retinol exposure did not cause any cytotoxicity to cardiac fibroblasts under normal conditions. However, retinol-mediated suppression of fibroblast viability under ischemic conditions could only be reversed by exposure to oxygen, glutamine and glucose at normal levels. Thus, it was evident that retinol acted as antiproliferative agent for fibroblasts only under ischemic conditions.

Hydroxyproline level in myocardial tissues is considered an indicator of mature collagen granules [13]. It has been reported that targeting of androgen receptor led to development of fibrosis, indicating the involvement of androgen receptor in the fibrotic process [14]. Cardiac fibroblasts generally undergo proliferation under conditions of glucose deprivation, and the same property is associated with development of 
fibrosis [15]. In the present study, AMI in mice led to a significant elevation in hydroxyproline level in the myocardial tissues. However, on treatment with retinol, the AMl-mediated elevation of hydroxyproline level was effectively reversed in myocardial tissues of mice. This indicates suppression of the proliferation of cardiac fibroblast by retinol under ischemia, thereby inhibiting fibrosis via targeting hydroxyproline production in AMI mice.

Studies have demonstrated the key role of TNF$\alpha$ and interleukins in tissue damage associated with myocardial infarction [16]. The production of TNF- $\alpha$ in myocardial tissues of ischemic animals has been shown to be markedly elevated, when compared to normal animals [17]. Overexpressed TNF- $\alpha$ level in patients with AMI mediates inflammation [18]. Moreover, elevated TNF- $\alpha$ levels in myocardial tissues induce dysfunction of cardiac myocytes [19]. In the present study, there were marked increases in TNF-a levels in cardiac tissues of AMI mice, when compared with normal mice. However, in retinol treated-mice, the AMI-induced increases in TNF- $\alpha$ levels in cardiac tissues were significantly suppressed.

Gap junction proteins are associated with signal transduction of amongst different cells [20]. The major proteins which form these gap junctions are connexins, amongst which $\mathrm{Cx} 43$ is present mainly in cardiac tissues [21]. Studies have shown reduced $\mathrm{Cx43}$ expression in cardiac tissues of myocardial infarction patients [21]. The current study also found relatively low Cx43 protein levels in myocardial tissues of mice subjected to AMI. Moreover, Cx43 protein distribution in ventricular tissues of AMI mice was random and prominently reduced, when compared to that in normal mice. However, Cx43 protein distribution was uniform and higher in ventricular tissues of normal mice. Moreover, retinol treatment of AMI mice caused significant reversal of the AMI-induced down-regulation of Cx43 proteins.

\section{CONCLUSION}

Retinol acts as anti-proliferative compound for fibroblasts under ischemic conditions, and prevents fibrosis in mice with AMI. Furthermore, retinol targets TNF- $\alpha$ production and promotes Cx43 expression in myocardial tissues of AMI mice. These findings suggest that retinol mitigated myocardial damage associated with AMI in mice. Therefore, retinol may be potentially beneficial for the treatment of myocardial infarction.

\section{DECLARATIONS}

\section{Conflict of interest}

No conflict of interest is associated with this work.

\section{Contribution of authors}

We declare that this work was done by the authors named in this article, and all liabilities pertaining to claims relating to the content of this article will be borne by the authors. Hao Sun, Jiuchang Zhong, Xinchun Yang, Zongsheng Guo, Jiamei Liu, Boqia Xie, Yuan Zhang, Xin Wang, Linying Shi performed the experimental work. Hao Sun, Jiuchang Zhong and Xinchun Yang carried out literature survey. Jiamei Liu, Boqia Xie and Yuan Zhang analysed and compiled the data. Mulei Chen designed the study and wrote the manuscript. All the authors read the paper thoroughly and approved it for publication.

\section{Open Access}

This is an Open Access article that uses a funding model which does not charge readers or their institutions for access and distributed under the terms of the Creative Commons Attribution License (http://creativecommons.org/licenses/by/ 4.0) and the Budapest Open Access Initiative (http://www.budapestopenaccessinitiative.org/rea d), which permit unrestricted use, distribution, and reproduction in any medium, provided the original work is properly credited.

\section{REFERENCES}

1. Sun $R$, Zhang $D$, Zhang J, Feng $Q$, Zhang $Y$, Zhao $C$, Zhang $W$. Different effects of lysophosphatidic acid on L-type calcium current in neonatal rat ventricular myocytes with and without $\mathrm{H} 2 \mathrm{O} 2$ treatment. Prostaglandins Other Lipid Mediat 2015; 118-119.110.

2. Jiabao H, Qing Z, Runchang W, Hongyan J, Yusi C, Xiaoqing $Q$, Cuntai Z. Systemic Immune-Inflammatory Index Predicts Clinical Outcomes for Elderly Patients with Acute Myocardial Infarction Receiving Percutaneous Coronary Intervention. Med Sci Monit 2019; 25:9690-9701.

3. Leask A. Potential therapeutic targets for cardiac fibrosis: TGFbeta, angiotensin, endothelin, CCN2, and PDGF, partners in fibroblast activation. Circ Res 2010; 106 : 1675-1680.

4. Van den Borne SW, Diez J, Blankesteijn WM, Verjans J, Hofstra L. Myocardial remodeling after infarction: the role of myofibroblasts. Nat. Rev Cardiol 2010; 7: 30-37. 
5. Sharain K, Vasile VC, Jaffe AS. Does cardiac rhythm monitoring in patients with elevated troponin levels lead to changes in management. Eur Heart $J$ Acute Cardiovasc Care 2016; 27: (Epub ahead of print).

6. Latet SC, Hoymans VY, Van Herck PL, Vrints CJ. The cellular immune system in the post-myocardial infarction repair process. Int J Cardiol 2015; 179: 240-247.

7. Hansson GK. Inflammatory mechanisms in atherosclerosis. J Thromb Haemostasis 2009; 7 (Suppl 1): 328-331.

8. Lin CC, Lin CE, Lin YC, Ju TK, Huang YL, Lee MS, Chen $\mathrm{JH}$, Lee $H$. Lysophosphatidic acid induces reactive oxygen species generation by activating protein kinase $C$ in PC-3 human prostate cancer cells. Biochem Biophys Res Commun 2013; 440: 564-569.

9. De Mello WC, Specht P. Chronic blockade of angiotensin II AT1receptors increased cell-to-cell communication, reduced fibrosis and improved impulse propagation in the failing heart. J Renin Angiotensin Aldosterone Syst 2006; 7: 201-205.

10. Tomitsuka E, Kita K, Esumi H. An anticancer agent, pyrvinium pamoate inhibits the NADH-fumarate reductase system--a unique mitochondrial energy metabolism in tumour microenvironments. I Biochem 2012; 152: 171-183.

11. Visconti RP, Richardson $C D$, Sato $T N$. Orchestration of angiogenesis and arteriovenous contribution by angiopoietins and vascular endothelial growth factor (VEGF). Proc Natl Acad Sci U S A 2002; 99: 8219-8224.

12. Kobayashi $K$, Luo $M$, Zhang $Y$, Wilkes DC, Ge G. Secreted Frizzled-related protein 2 is a procollagen $C$ proteinase enhancer with a role in fibrosis associated with myocardial infarction. Nat Cell Biol 2009; 11: 46-55.

13. Motoaki Murakoshi, Kyohei Saiki, Kyoji Urayama, Thomas $N$ Sato: An Anthelmintic Drug, Pyrvinium Pamoate, Thwarts Fibrosis and Ameliorates Myocardial Contractile Dysfunction in a Mouse Model of Myocardial Infarction. Plos One 2013; 8: e79374.
14. Ikeda $Y$, Aihara K, Sato T, Akaike M, Yoshizumi M. Androgen receptor gene knockout male mice exhibit impaired cardiac growth and exacerbation of angiotensin II-induced cardiac fibrosis. J Biol Chem 2005; 280(33): 29661-29666.

15. Chun MG, Shaw RJ. Cancer metabolism in breadth and depth. Nat Biotechnol 2013; 31: 505-507.

16. Putko BN, Wang Z, Lo J, Anderson T, Becher H, Dyck JR, Kassiri Z, Oudit GY. Alberta HEART Investigators: Circulating levels of tumor necrosis factor-alpha receptor 2 are increased in heart failure with preserved ejection fraction relative to heart failure with reduced ejection fraction: Evidence for a divergence in pathophysiology. PLoS One 2014; 9: e99495.

17. Moreira DM, da Silva RL, Vieira JL, Fattah T, Lueneberg $M E$, Gottschall CA. Role of vascular inflammation in coronary artery disease: Potential of anti-inflammatory drugs in the prevention of atherothrombosis. Inflammation and anti-inflammatory drugs in coronary artery disease. Am J Cardiovasc Drugs 2015; 15: 1-11.

18. Chang WT, Wang YC, Chen CC, Zhang SK, Liu CH, Chang FH, Hsu LS. The -308G/A of tumor necrosis factor (TNF)- $\alpha$ and $825 C / T$ of guanidine nucleotide binding protein 3 (GNB3) are associated with the onset of acute myocardial infarction and obesity in Taiwan. Int J Mol Sci 2012; 13: 1846-1857.

19. Petkova-Kirova PS, London B, Salama G, Rasmusson RL, Bondarenko VE. Mathematical modeling mechanisms of arrhythmias in transgenic mouse heart overexpressing TNF- $\alpha$. Am J Physiol Heart Circ Physiol 2012; 302: H934-H952.

20. Hirata N, Kanaya N, Kamada N, Kimura S, Namiki A. Differential effects of propofol and sevoflurane on ischemia-induced ventricular arrhythmias and phosphorylated connexin 43 protein in rats. Anesthesiology 2009; 110: 50-57.

21. Nielsen MS, Axelsen LN, Sorgen PL, Verma V, Delmar M, Holstein-Rathlou NH. Gap junctions. Compr Physiol 2012; 2: 1981-2035. 